\title{
VALUE PREMIUM IN THE CHINESE STOCK MARKET: FREE LUNCH OR PAID LUNCH?
}

\author{
Yujia Huang \\ Renmin University of China \\ Jiawen Yang \\ The George Washington University
}

In this paper we examine the time-series predictability of the book-to-market $(B / M)$ ratio for annual and monthly portfolio returns in the Chinese stock market. We find that value premiums exist throughout our sample period of 1998 to 2008. However, the predictability of B/M appears to be unrelated with financial distress risk. In fact, value stocks are less risky than growth stocks in terms of return volatility and estimated financial distress risk. Further, our results suggest that the factor $\mathrm{VMG}$, which is directly related to value premium, is not a pervasive risk measure compared to market factor and SMB. While the size effect seems to be closely related to distress risk, both size and $\mathrm{B} / \mathrm{M}$ factors do not appear to be driven by financial distress risk.

\section{INTRODUCTION}

Research on the value premium touches upon the most basic question of trading in the capital market: Where does the value premium come from? Scholars who believe in rational pricing hope to justify the return patterns by risk. If higher returns are compensation for higher risks, the value premium in the market is fair play - There should be no free lunch in an investment strategy. In their seminal paper Fama and French (1993) construct a three-factor model (SMB and HML, also known as VMG, in addition to the market factor) to absorb the excess return that is left unexplained by the capital asset pricing model (CAPM). They suggest that the SMB and HML factors may be proxies for the pervasive distress risk. Portfolios of small and value stocks have higher returns because they have higher risk loadings on the two factors. Fama and French (1995) and Chen and Zhang (1998) subsequently prove that value stocks exhibit many properties that represent distress status, such as persistent low earnings, high leverage, and big earnings uncertainty. Fama and French (1998) also show that a two-factor model that includes a risk factor for relative distress captures the value premium in international returns.

In contrast to the risk premium hypotheses, another strand of the literature on the value premium suggests that the excess returns are not due to distress risk, but to mispricing. According to Dichev (1998) and Campbell, Hilscher and Szilagyi (2008), financially distressed firms seem to deliver abnormally lower return than their counterparts, which suggests that the distress risk may not be a systematic risk. Moreover, Griffin and Lemmon (2002) break down the stock returns between low and high $\mathrm{B} / \mathrm{M}$ firms and find that the group of firms with the highest distress risk includes more low $\mathrm{B} / \mathrm{M}$ firms than high $\mathrm{B} / \mathrm{M}$ firms. Their finding favors the mispricing view for value premium.

This research is carried out while Yujia Huang stayed at the George Washington University as a visiting scholar from September 2009 to September 2010. Email: wataxi0101@gmail.com. Dr. Yang is a professor of International Business at the George Washington University. Email: jwyang@gwu.edu. 
Fama and French (2007) provide another possible explanation for the value premium. The value premium may reflect investors' heterogeneous tastes for some particular asset characteristics, which are unrelated to properties of returns. In summarizing the studies on the value premium, Fama (2010) points out the weakness of each major explanation. The risk story fails to pinpoint certain state variables that lead to variations in expected returns. As for the mispricing position, it requires the presumption that the investors never learn about their behavioral biases, while the "investors' taste explanations" also requires that the tastes should persist and have persistent effect on expected returns as long as these tastes do not lead to arbitrage opportunities.

Prior studies on value premium have focused on stock markets in advanced economies, particularly the United States. Our objective in this study is to investigate whether value premium exists in the Chinese stock market and find plausible explanations for such a phenomenon if it does exist. Compared to the US market, the Chinese market has a unique investor structure in that it contains a large fraction of individual investors. It was not until the end of 2008 that the proportion of institutional investors passed beyond the proportion of individual investors. The dominance of naive individual investors cast a strong atmosphere of short-term speculation in the Chinese stock market. We are curious whether the value strategy that supports long term contrarian investment elsewhere also produces a significant and persistent value premium in such a market.

Upon evaluating the one- to five-year returns for $\mathrm{B} / \mathrm{M}$ portfolios, we find that the $\mathrm{B} / \mathrm{M}$ anomaly does exist in the Chinese stock market. We also find that the return spread between the highest $\mathrm{B} / \mathrm{M}$ group and the lowest $\mathrm{B} / \mathrm{M}$ group is increasing over the five year period. However, the marginal increase of the spread begins to shrink from the fourth year.

We find that the value premium in the Chinese market differs in characteristics compared with that of the US market. Firms with high $\mathrm{B} / \mathrm{M}$ values have relatively lower financial leverage, and produce almost no different earnings from firms with low B/M values, while value firms in the US market have higher financial leverage, lower earnings, and bigger earning uncertainties.

We find significant $\mathrm{B} / \mathrm{M}$ effects in their performance when stratify portfolios with firm size and $\mathrm{B} / \mathrm{M}$ ratios. While small firms have persistently higher stock returns, they do display higher risk exposure than big stocks. For example, they have significantly higher standard deviations for portfolio returns, higher financial leverage, lower accounting earnings, and higher fitted distress probability than big firms. However, when we compare the characteristics between value and growth stocks, we find completely different results. While the stock returns increase monotonically with B/M value, their standard deviations actually decrease. Firms with high B/M value display lower financial leverage, and show no significant difference in earnings and fitted distress probability from firms with low B/M firms. Overall, although size is closely related to financial distress risk, neither size nor the value premium appears to support the distress risk hypothesis in the Chinese stock market.

Our finding of the persistent return spreads between value and growth firms renders support for the mispricing hypothesis rather than the distress risk hypothesis. In contrast with the strong explanatory power of VMG (also known as HML) for the US stock market, VMG in this study is quite unstable in our unconditional and conditional regressions, which puts VMG under the challenge that it may not be a proxy for pervasive risk in the Chinese stock market. If a factor is priced and proxies for a certain systematic risk, we expect to find statistical and economical 
significance in the risk and return relation. Higher risk is a necessary and sufficient condition for higher return only if the risk is systematic, which leads to a strictly positive relation between risk and return. On the contrary, if the risk is diversifiable, higher return with higher risk is only a sufficient condition that higher returns are accompanied by higher risk but the higher risk does not necessarily assure a higher return. Moreover, if a certain persistent return pattern is due to reasons other than a systematic risk (e.g., mispricing), our empirical results will show up differently. If mispricing exists, it will eventually be corrected after certain some time and the VMG factor will show unstable performance as we change the formation of portfolios.

The remainder of the paper is organized as follows. Section 2 describes the data we use in the empirical tests, and presents summary statistics, and introduces our research design for the regression tests. Section 3 presents the results of our investigation of value premium in the Chinese stock market and our test of the relation between distress risk and value premium. Section 4 summarizes our main findings and conclusions.

\section{RESEARCH DESIGN}

\subsection{Data and sorts}

Our dataset includes all nonfinancial A-shares listed on the Shanghai and Shenzhen Stock Exchanges from 1997-2008. The monthly and annual stock returns, the accounting and market data to compute the book-to-market ratios, as well as the risk-free rate in our dataset are from the China Stock Market and Accounting Research Database (CSMAR).

Following the literature, we use both sorts and regressions in this study. We sort stocks into portfolios according to book-to-market ratio (B/M), size, and industry. At the end of each year from 1997 to 2007, we sort all stocks in an ascending order based on their B/M values and allocate them into ten groups according to their deciles. Both the book and market values that are used to compute the $\mathrm{B} / \mathrm{M}$ ratio are taken for the end of the previous fiscal year. The size portfolios are also formed into ten deciles based on the year-end market values of the stocks from 1997 to 2007. In addition, we classify all the stocks into 12 industry portfolios according to the industry code published by the China Securities Regulatory Commission as reported in CSMAR (financial industry is excluded). By allocating stocks into size portfolios, we can control the variation in market value which is directly related to financial risks (Lewellen, 1999). By allocating stocks into different industries, we can get a relatively neutral classification that is less susceptible to data-mining problems in a robustness check.

We examine both the annual and monthly returns for the portfolios. For the annual portfolio returns, a stock must have book value of equity and market capitalization at the end of December of year T-1 to compute its book-to-market ratio. Consequently, we look at portfolios formed every year starting from 1997 . We compute the equally weighted return of all the stocks within each portfolio, and look at one- to five-year's buy-and-hold returns after the portfolio formation. For monthly returns, according to Lakonishok, Shleifer and Vishny (1994), using annual rebalanced portfolios could avoid various microstructure issues and execution costs, and can produce returns that are closer to those that investors can actually capture. As a result, we use the annual division of $\mathrm{B} / \mathrm{M}$ portfolios instead of monthly rebalanced portfolios for monthly returns.

According to Fama and French (2008), although sorts seem to be a clumsy methodology and are awkward for drawing inferences about which anomaly variables have unique information 
about average returns, it does depict a simple picture of how average returns vary across the spectrum of an anomaly variable. On the other hand, while the results of regression methodology tend to weigh towards the small stocks that make the majority number of the market, multiple regression slopes do provide direct estimate of marginal effects. We use both methods to examine the stock performance in the Chinese stock market.

\subsection{Book-to-market $(\mathrm{B} / \mathrm{M})$ and stock returns}

2.2.1 Annual returns. We examine the $\mathrm{B} / \mathrm{M}$ sorted portfolios for five years after their formation. Specifically, we look at the returns in three measures: (1) the annual returns for each of the five years; (2) the buy-and-hold returns for one to five years; and (3) the year-by-year buyand-hold return differences between high $\mathrm{B} / \mathrm{M}$ and low $\mathrm{B} / \mathrm{M}$ firms. The buy-and-hold return for portfolio in any particular year is defined as $R_{i T}=\left[\Pi\left(1+r_{i T}\right)-1\right]$, where $r_{i T}$ is the annual return for portfolio $\mathrm{i}$ in year $\mathrm{T}$. We include the year-by-year return comparison to see whether the return pattern changes over time and whether the value premiums are robust in different market situations.

2.2.2 Time-series predictability of $B / M$ on monthly returns. We use two measures to examine the relation between $\mathrm{B} / \mathrm{M}$ values and stock returns - descriptive statistics and regression analysis. Descriptive statistics provide an intuitive overview of the basic features of the $\mathrm{B} / \mathrm{M}$ value and return relationship. The regression model is specified as follows:

$$
M R_{i t, T}=\alpha_{i}+\lambda_{i} \ln B / M_{i, T-1}+\mu_{i t},
$$

where $M R_{i t, T}$ is the monthly excess return of portfolio $\mathrm{i}$ at month $\mathrm{t}$ in year $\mathrm{T}, \ln B / M_{i, T-1}$ is the natural $\log$ of $B / M$ value at the end of year $\mathrm{T}-1$, and $\mu_{i t}$ is the residual. In addition to the $\mathrm{B} / \mathrm{M}$ portfolio, we also employ the size and industry portfolios to test the monthly returns predictability and the unconditional and conditional models, as specified later in the paper.

\subsection{Distress risk factor proxies}

To see if value premium, if it does exist, is a reward for distress financial risk, we need to develop such risk factors. We derive our measures of the financial distress risk from existing research and incorporate some distinctive features of the Chinese stock market. Two different ways of ranking firms on bankruptcy probability are frequently applied in the literature: multiple discriminant analysis (MDA) (e.g., Altman's Z-score) and conditional logit regressions (CLR) (e.g., Ohlson's O-score). We follow the latter methodology to estimate the probabilities of distress for an individual firm. We specify the distress probability over time as follows:

$$
P_{T}\left(y_{i T}=1\right)=\frac{1}{1+e^{-\left(\alpha+\beta X_{i T-1}\right)}},
$$

where $x_{i T-1}$ is a vector of predicting variables in year T-1, $\mathrm{y}$ is the indicator of distress risk. Normally, y would assume a value of 1 if the firm defaults and zero otherwise. However, in the case of China, regulation permits insolvent firms to continue their listing and trading in the stock market with a "special treatment" (ST) status until it recovers or delisted. ${ }^{1}$ Thus, if firm i is put

\footnotetext{
${ }^{1}$ According to stock market regulations in China, a firm is considered to be in a bankrupt status if it is designated under "special treatment" (ST). However, the stock is not delisted from the stock market until it practically ceases operation. Until June 1st, 2010, only 72 stocks were delisted from the Shanghai and Shenzhen Stock Exchanges out of 1824 listed firms.
} 
under "special treated (ST)" and thus becomes an ST stock in year T, $y_{i}=1$; if firm i stays solvent, $y_{i}=0$. By maximizing the following log likelihood function

$$
\ln L(\alpha, \beta)=\sum_{i}\left\{y_{i T} \ln P\left(X_{i T-1}, \beta\right)+\left(1-y_{i T}\right) \ln \left(1-P\left(X_{i T-1}, \beta\right)\right)\right\},
$$

we estimate $\alpha$ and $\beta$, and calculate the distress probability for each firm.

We need accounting measures of the predicting variables for financial distress in our logit model. Based on the existing literature of financial distress risk prediction, we select six measures - CASHTA, OPCAPTA, ROA, TATNOV, CURR, and DTA, each representing a different aspect of a firm being financially distressed. CASHTA is the ratio of cash over total assets at the end of each year. A firm with high CASHTA is less prone to liquidity risk when large amount of long-term debt or interest is due in the near future. OPCAPTA is the ratio of operating capital over total assets. Higher proportion of operating capital indicates better shortterm solvency. ROA is the net income divided by total asset. This ratio is incorporated to measure firms' profitability. TATNOV is the turnover ratio of total assets, indicating the efficiency of assets in terms of sales. CURR is the current ratio computed as the difference between current asset and current liability divided by the current asset. Presumably, firms with higher current ratios are less likely to experience financial distress, because it indicates that higher proportion of short-term assets are financed by long-term debts. However, a firm would also suffer from low profitability if its current ratio gets too high and the short-term assets overoccupy the long-term debts. DTA is a firm's leverage ratio, computed as the total liability divided by total assets. Higher leverage means higher bankruptcy risk as suggested by the classic corporate finance literature.

\subsection{Unconditional and conditional models}

Following Lewellen (1999), we construct a set of unconditional and conditional models to test the risk hypothesis for value premium. We employ the Fama and French three-factor model as our unconditional model, which test the empirical performance of a static model. The unconditional model is estimated under the assumption of no change in the factor loadings and expected returns. However, the expected returns and the factor loadings in the real world may vary over time. In our conditional model, we allow both the factor loadings and expected returns to change over time to see if the results are time variant.

2.4.1 The unconditional model. Merton (1973) requires an explanation for the return anomalies to consist of priced factors that are orthogonal to market returns. Accordingly, we obtain the Fama and French factors that are orthogonal to the market excess returns, SMBO and HMLO, and use them as regressors in both our unconditional and conditional models. The unconditional model is specified as follows:

$$
R_{i}-R_{f}=a_{u}+b_{u}\left(R_{m}-R_{f}\right)+s_{u} S M B O+v_{u} V M G O+\varepsilon_{i},
$$

where $R_{i}-R_{f}$ is the monthly excess return of portfolio i, computed as the difference between portfolio return and risk-free rate, and $R_{m}-R_{f}$ is the market excess return. We convert the threemonth term deposits interest rate into monthly rate as our risk-free rate. ${ }^{2}$ SMBO is the return on

\footnotetext{
${ }^{2}$ The one-month Treasury bill rate is often used as the risk-free rate in studies on US stock market. However, there is no equivalent one-month T-bill rate in China. So we use the one-month bank deposit rate as our risk-free rate.
} 
the small size portfolio minus the return on the big size portfolio, orthogonalized with respect to the market excess return. VMGO is the return on portfolio of the highest $30 \% \mathrm{~B} / \mathrm{M}$ stocks minus the lowest $30 \% \mathrm{~B} / \mathrm{M}$ stocks, orthogonalized with respect to the market excess return. ${ }^{3}$ For simplicity, we omit the time subscriptions in our model.

2.4.2 The conditional model. Chan and Chen (1991) and Fama and French (1995) suggest that small stocks and stocks with high $\mathrm{B} / \mathrm{M}$ values may generate higher returns because they bear higher distress risk that cannot be diversified away through time. Suppose the coefficients of the three factors are linearly related to the distress probability. We then follow Lewellen (1999) to specify our conditional model as

$$
\begin{aligned}
R_{i}-R_{f}= & a_{i}+a_{i c} \pi_{i}+\left(b_{i}+b_{i c} \pi_{i}\right)\left(R_{m}-R_{f}\right) \\
& +\left(s_{i}+s_{i c} \pi_{i}\right) S M B O+\left(v_{i}+v_{i c} \pi_{i}\right) V M G O+\varepsilon_{i}
\end{aligned}
$$

Or,

$$
\begin{aligned}
R_{i}-R_{f}= & a_{i}+a_{i c} \pi_{i}+b_{i}\left(R_{m}-R_{f}\right)+s_{i} S M B O+v_{i} V M G O+ \\
& b_{i c} \pi_{i} *\left(R_{m}-R_{f}\right)+s_{i c} \pi_{i} * S M B O+v_{i c} \pi_{i} * V M G O+\varepsilon_{i}
\end{aligned}
$$

where $\pi$ is the predicted financial distress risk estimated by the logit model. Again we drop the time subscripts to reduce clutter. Other variables are defined the same as in our unconditional model.

2.4.3 Discussion. The results of the unconditional and conditional model regressions should reveal the driving forces behind the small and value stock returns. First of all, SMB and VMG proposed by Fama and French (1993) are directly designed to mimic the underlying risk factors for size and $\mathrm{B} / \mathrm{M}$ premiums. If they are proxies for certain systematic risk, the coefficients of SMBO and VMGO should be statistically significant and robust across different portfolios in both regressions, because higher risk is compensated for higher return only if this risk is systematic. Otherwise, the risk could be diversified away through time and through different portfolios formations, and couldn't survive in a statistical test. However, if the coefficients for one or both factors demonstrate big variation in its explanatory power across portfolios and time, we have reason to cast doubt on one or both factors as pervasive risk factors. Secondly, if, empirically, one or both factors turn out to indicate the existence of certain systematic risks, what risks do they proxy for? Chan and Chen (1991) and Fama and French (1995) suggest that small and value stocks are assigned a higher premium because of a greater financial distress risk. However, more recent studies (Lakonishok, Shleifer and Vishny (1994), Dichev (1998), Griffin and Lemmon (2002), Ang, Hodrick, Xing and Zhang (2006) and Campbell, Hilscher, Szilagyi (2008)) show inconsistent evidence with the risk-based explanations. If the risk story is right, after introducing the distress probability and its intersection terms with the three Fama and French factors, we would expect the coefficient of the distress probability, $a_{i c}$, to be significantly different from zero, and the coefficients of the intersection terms between SMBO and VMGO and the distress risk measure to be non-zero as well, indicating that those two factors are indeed related to the distress risk. However, if our empirical results do not show persistent non-zero

When the interest rate changes in the middle of the month, we adjust the weight according to the days before and after the changes in that period.

${ }^{3}$ The Fama and French factors are separately regressed on a constant and the excess market return, and those two orthogonal factors are the sum of the regression's intercepts and residuals respectively. 
results for these coefficients, there is indication that something else (e.g., mispricing) is the driving force of the size and value premium.

\section{RESULTS AND DISCUSSIONS}

3.1 B/M's predictability on annual returns and value premium

3.1.1 Value and growth stocks. We allocate all listed stocks in the Shanghai and Shenzhen Stock Exchanges into deciles. According to the literature, stocks with the highest B/M ratios in the portfolio are referred to as value stocks and those with the lowest $\mathrm{B} / \mathrm{M}$ ratios are called growth or glamour stocks. We remove observations with negative $\mathrm{B} / \mathrm{M}$ ratios as they are noisy to our sample.

In Table 1, we present the average annual returns during the one to five years after the portfolio formation date from 1998 to 2008, which are computed as the arithmetic averages of the annual returns. We observe an apparent reversal effect from year 0 to year 1 after the portfolio formation. The average returns at year $0, \mathrm{AR}_{0}$, shows a negative relation between the average returns and the $\mathrm{B} / \mathrm{M}$ ratio. That is, lower $\mathrm{B} / \mathrm{M}$ ratios are associated with higher average annual returns. However, the return patterns turn around at year 1 and show a positive value premium from year 1 through year 5. The average annual return is 0.21 for glamour stocks and 0.32 for value stocks over the 5-year post-formation period.

\section{Table 1 Average annual returns among different B/M portfolio, 1998-2008}

This table shows the one to five years' annual returns of the B/M portfolios from 1998-2008. At the end of each year T (1997-2007), all stocks listed on the the Shanghai and Shenzhen Stock Exchanges are allocated into ten portfolios in ascending order based on $\mathrm{B} / \mathrm{M}$. B/M is the ratio of the book value of equity to market value of equity. Year 0 is the portfolio formation year. $\mathrm{AR}_{\mathrm{T}}$ is the average annual return over the Tth year after portfolio formation, $\mathrm{T}=1, \ldots, 5$. AR is the average return across different periods from year 1 to year 5 . Value premium is the return spread between the highest $\mathrm{B} / \mathrm{M}$ portfolio minus the lowest $\mathrm{B} / \mathrm{M}$ portfolio.

\begin{tabular}{|c|c|c|c|c|c|c|c|c|c|}
\hline Group & Obs. & $\mathrm{B} / \mathrm{M}$ & $\mathrm{AR}_{0}$ & $\mathrm{AR}_{1}$ & $\mathrm{AR}_{2}$ & $\mathrm{AR}_{3}$ & $\mathrm{AR}_{4}$ & $\mathrm{AR}_{5}$ & AR \\
\hline growth & 1235 & 0.10 & 0.56 & 0.14 & 0.16 & 0.41 & 0.13 & 0.22 & 0.21 \\
\hline 2 & 1228 & 0.17 & 0.42 & 0.20 & 0.20 & 0.53 & 0.16 & 0.23 & 0.26 \\
\hline 3 & 1200 & 0.21 & 0.33 & 0.20 & 0.20 & 0.48 & 0.17 & 0.23 & 0.26 \\
\hline 4 & 1170 & 0.25 & 0.28 & 0.22 & 0.23 & 0.52 & 0.14 & 0.24 & 0.27 \\
\hline 5 & 1192 & 0.28 & 0.21 & 0.22 & 0.23 & 0.54 & 0.20 & 0.27 & 0.29 \\
\hline 6 & 1203 & 0.32 & 0.17 & 0.25 & 0.24 & 0.54 & 0.19 & 0.24 & 0.29 \\
\hline 7 & 1202 & 0.36 & 0.13 & 0.28 & 0.29 & 0.54 & 0.20 & 0.29 & 0.32 \\
\hline 8 & 1229 & 0.41 & 0.11 & 0.23 & 0.26 & 0.54 & 0.18 & 0.29 & 0.30 \\
\hline 9 & 1269 & 0.47 & 0.08 & 0.26 & 0.26 & 0.52 & 0.21 & 0.27 & 0.30 \\
\hline Value & 1278 & 0.62 & 0.05 & 0.27 & 0.28 & 0.58 & 0.20 & 0.29 & 0.32 \\
\hline \multicolumn{2}{|c|}{ Value premium- } & - & -0.51 & 0.13 & 0.13 & 0.17 & 0.08 & 0.07 & 0.11 \\
\hline
\end{tabular}

We also notice that the annual return spread between value and glamour stocks are narrowing from $13 \%$ in year 1 to $7 \%$ in year 5 . This is consistent with the stock migration effect observed by Fama and French (2007). If stocks that are first allocated in the value stocks portfolio earn relatively higher returns than the glamour stocks, these value stocks may gradually migrate into the glamour portfolios with higher market value and lower $\mathrm{B} / \mathrm{M}$ ratios, resulting in a 
return reversal.

In Table 2, we present the buy-and-hold returns for year 1 through year 5 after the portfolio formation. It is obvious that through year 1 to year 5, the longer the portfolio is held, the larger rewards one could expect. The average accumulative stock return for five years is 2.98 for the value group and 1.57 for the growth group, with a spread as high as 0.73 .

\section{Table 2 Average buy-and-hold returns among different B/M portfolio, 1998-2008}

This table shows one to five years' buy-and-hold returns of the B/M portfolio from 1998-2008. Portfolio formation is rebalanced at the end of each year. $\mathrm{AER}_{\mathrm{T}}$ is the cumulative buy-and-hold return over $\mathrm{T}$ years after portfolio formation, $\mathrm{T}=1, \ldots, 5$. The buy-and-hold return for portfolio i at year $\mathrm{T}$ is $R_{i T}=\left[\Pi\left(1+r_{i T}\right)-1\right]$, where $r_{i T}$ is the annual return for portfolio i in year T. AER is the average buy-and-hold return across different periods for a particular portfolio from year 1 to year 5

\begin{tabular}{|c|c|c|c|c|c|c|c|c|c|}
\hline Group & Obs. & $\mathrm{B} / \mathrm{M}$ & $\mathrm{AER}_{0}$ & $\mathrm{AER}_{1}$ & $\mathrm{AER}_{2}$ & $\mathrm{AER}_{3}$ & $\mathrm{AER}_{4}$ & $\mathrm{AER}_{5}$ & AER \\
\hline Growth & 1235 & 0.10 & 0.56 & 0.14 & 0.32 & 0.86 & 1.11 & 1.57 & 0.80 \\
\hline 2 & 1228 & 0.17 & 0.42 & 0.20 & 0.44 & 1.20 & 1.56 & 2.14 & 1.11 \\
\hline 3 & 1200 & 0.21 & 0.33 & 0.20 & 0.44 & 1.13 & 1.49 & 2.07 & 1.07 \\
\hline 4 & 1170 & 0.25 & 0.28 & 0.22 & 0.50 & 1.28 & 1.60 & 2.22 & 1.17 \\
\hline 5 & 1192 & 0.28 & 0.21 & 0.22 & 0.50 & 1.31 & 1.77 & 2.52 & 1.27 \\
\hline 6 & 1203 & 0.32 & 0.17 & 0.25 & 0.55 & 1.39 & 1.84 & 2.52 & 1.31 \\
\hline 7 & 1202 & 0.36 & 0.13 & 0.28 & 0.65 & 1.54 & 2.05 & 2.94 & 1.49 \\
\hline 8 & 1229 & 0.41 & 0.11 & 0.23 & 0.55 & 1.39 & 1.82 & 2.63 & 1.32 \\
\hline 9 & 1269 & 0.47 & 0.08 & 0.26 & 0.59 & 1.41 & 1.92 & 2.71 & 1.38 \\
\hline Value & 1278 & 0.62 & 0.05 & 0.27 & 0.63 & 1.57 & 2.08 & 2.98 & 1.50 \\
\hline \multicolumn{2}{|c|}{ Value premium - } & - & -0.51 & 0.13 & 0.28 & 0.49 & 0.61 & 0.73 & 0.45 \\
\hline
\end{tabular}

Moreover, by comparing the return spreads between the value and growth portfolios from year 0 to year 1 , there is clearly a premium for a contrarian strategy. In year 0 , the average return decreases monotonically from the growth portfolio to the value portfolio and produces a value premium of -0.51 , while in year 1 , the average return increases monotonically from the growth portfolio to the value portfolio and produces a value premium of 0.13 .

3.1.2 Year-by-year value premiums Table 3 reports the year-by-year returns of value strategy from 1998 to 2008 . When considered separately in each year, the value premium stays positive for short and long holding periods for all years except for the 1-year and 2-year returns for portfolios starting in 1999. In sum, the value premium is not subject to time changes or market conditions in our sample periods.

3.1.3 Value premiums in bad times. Lakonishok, Shleifer and Vishny (1994) (referred to as LSV hereafter) find that value stocks outperform glamour stocks in 19 out of 22 years in their sample. According to LSV, value stocks would be fundamentally riskier than glamour stocks if, first, they underperform glamour stocks in some states of the world, and second, those are on average "bad" states, in which the marginal utility of wealth is high. In this section, we look at the value strategy over different times including times of severe market declines, in which the marginal utility of consumption is supposed to be high. 


\section{Table 3 Year-by-year returns of high B/M firms minus low B/M, 1998-2008}

This table shows one to five years' buy-and-hold return of B/M portfolio starting from each year between 1998 and 2008. At the end of each year T (1997-2007), all stocks are allocated into ten portfolios in ascending order based on B/M. The portfolios are rebalanced at the end of each year. Value premium in this table is the spread of the return for the highest $\mathrm{B} / \mathrm{M}$ portfolio over the return of the lowest $\mathrm{B} / \mathrm{M}$ portfolio. Market return is the excess market return between the value weighted market index and the one-month deposit rate.

\begin{tabular}{lllllll}
\hline \multirow{2}{*}{ Year } & \multicolumn{2}{l}{ market } & excess value premium & & & \\
& return & 1-year & 2-year & 3-year & 4-year & 5-year \\
\hline 1998 & 0.07 & 0.19 & 0.43 & 1.17 & 0.95 & 0.82 \\
1999 & 0.18 & -0.20 & -0.18 & 0.02 & 0.11 & 0.54 \\
2000 & 0.67 & 0.17 & 0.36 & 0.43 & 0.83 & 0.66 \\
2001 & -0.25 & 0.11 & 0.12 & 0.45 & 0.39 & 0.38 \\
2002 & -0.22 & 0.03 & 0.46 & 0.42 & 0.41 & 1.14 \\
2003 & -0.14 & 0.47 & 0.50 & 0.47 & 1.26 & 3.61 \\
2004 & -0.17 & 0.16 & 0.15 & 0.64 & 1.84 & 0.49 \\
2005 & -0.14 & 0.01 & 0.49 & 1.21 & 0.24 & - \\
2006 & 0.90 & 0.22 & 1.40 & 0.00 & - & - \\
2007 & 2.08 & 1.04 & 0.45 & - & - & - \\
2008 & -0.61 & 0.11 & - & - & - & - \\
Average & 0.22 & 0.21 & 0.42 & 0.53 & 0.75 & 1.09 \\
t-statistics & 1.06 & 2.79 & 2.33 & 3.59 & 3.42 & 2.39 \\
\hline
\end{tabular}

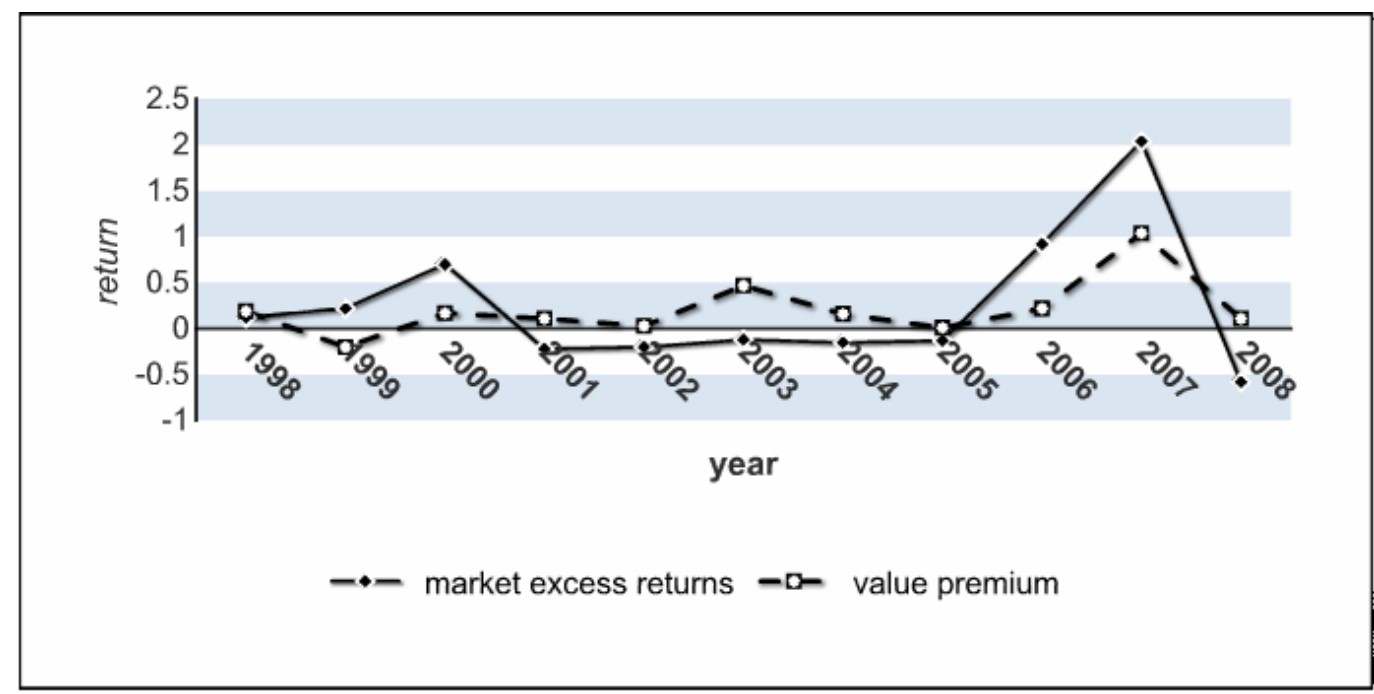

Figure 1. 1-year value premium and market excess returns.

At the end of each December from 1997 to 2007, ten groups of stocks are formed according to their $\mathrm{B} / \mathrm{M}$ ratios sorted in an ascending order. The value portfolio consists of stocks in the ninth and tenth groups, and the growth portfolio consists of stocks in the first and second groups. The 1-year value premium indicated by the dash line is the return spread between highest two groups and the lowest two groups. The market value weighted returns indicated by the solid line is the equal weighted market returns from CSMAR database, which shows the market ups and downs for the given year.

We depict the time series of the year-by-year value premium and the market excess return 
in Figure 1, which shows two interesting features. First, value stocks outperform glamour stocks in 10 out of 11 years. They also outperform the market return 7 out of 11 years. Secondly, the value premium demonstrates similar time-series characteristics with the excess market return. When the market goes up, the value premium rises quickly; and when the market goes down, the value premium drops yet remains positive. The Pearson correlation coefficient between the 1year value premium and the excess market return is 0.73 . This high correlation indicates that investors are sensitive to market risk changes. However, the value portfolio only underperforms the growth portfolio in one year, and the value premium remains significantly positive even when the market experiences obvious downwards in 2000 and 2008, which provide some inconsistent evidence towards the risk explanation for value premium.

\subsection{B/M Predictability on monthly returns}

Our foregoing discussions have focused on analysis of risk and annual returns. In the current section, we expand our analysis of this relation with monthly returns, size and industry effects. According to Lo and Mackinlay (1990), industry portfolios are less susceptible to the data-snooping issues. Lewellen (1999) suggests that size portfolios have the advantage that they control for changes in market values, which has been shown to be associated with risk and expected returns, yet relatively stable over time. In what follows, we first present summary statistics for stock returns and the lagged $\mathrm{B} / \mathrm{M}$ ratios. We then provide summary statistics for the monthly returns sorted by size and industry respectively. Portfolios sorted by the B/M ratio provide intuitive evidence for the relation between expected return and risk over time, while portfolios sorted by industry provide a classification that is relatively immune to the influence of size or the $\mathrm{B} / \mathrm{M}$ ratio.

3.2.1 Summary statistics for monthly returns. Table 4 presents summary statistics for the monthly stock returns and the $\mathrm{B} / \mathrm{M}$ ratios. We sort all stocks into ten $\mathrm{B} / \mathrm{M}$ portfolios, ten size portfolios and twelve industry portfolios. For all the three sets of portfolios, we compute the equally weighted monthly returns in the dataset.

For the industry portfolios, natural resource has the highest industry portfolio return $(1.99 \%)$, while the service industry has the lowest average return $(0.85 \%)$. The real estate industry exhibits the highest return volatility with a standard deviation of $22.23 \%$, while the transportation industry has the lowest standard deviation of $13.29 \%$. The industry portfolios show no obvious trade-off between volatility and reward. For the size portfolios, the portfolio returns and their standard deviations are monotonically decreasing with the increase in firm size. The group of firms in the smallest decile earns an average return of $1.77 \%$ per month with a standard deviation of $12.13 \%$ and the group of firms in the biggest decile earns an average return of $0.85 \%$ per month with a standard deviation of $9.42 \%$.

The return-risk relation in the $\mathrm{B} / \mathrm{M}$ sorted portfolios shows some interesting results. The average monthly returns range from $0.27 \%$ for growth stocks to $1.37 \%$ for value stocks. More interestingly, the average returns and their standard deviations demonstrate a negative relationship. When returns increase from the growth stocks to value stocks, the standard deviations drop from $15.65 \%$ to $14.00 \%$.

The difference in returns between the highest and lowest groups for the $\mathrm{B} / \mathrm{M}$ portfolios is $1.1 \%$, as compared to $1.14 \%$ for the industry portfolios and $0.92 \%$ for the size portfolios. The value premium and size premium produce similar return spreads in the Chinese stock market, and both the maximum and minimum returns in the size portfolios have higher values than the 
$\mathrm{B} / \mathrm{M}$ portfolio could produce. The variability of the standard deviations for the $\mathrm{B} / \mathrm{M}$ portfolios is smaller than that of the industry portfolios and is about the same with that of the size portfolios.

Table 4 Summary statistics for industry, size and B/M portfolios, 1998-2008

Panels A and B report summary statistics of portfolio returns sorted by B/M and size. At the end of each year between December 1997 to December 2007, 10-decile portfolios are respectively formed in ascending order based on book-to-market ratio and market value of the previous month. Panel $\mathrm{C}$ reports the results for industry portfolios.

\begin{tabular}{|c|c|c|c|c|c|}
\hline \multicolumn{3}{|c|}{ Panel A: B/M Portfolios } & \multicolumn{3}{|c|}{ Panel B: Size Portfolios } \\
\hline \multicolumn{3}{|c|}{ Return (\%) } & \multirow[b]{2}{*}{ portfolios } & \multicolumn{2}{|c|}{ Return (\%) } \\
\hline portfolios & Mean & Std.dev & & Mean & Std.dev \\
\hline Growth & 0.27 & 15.65 & Small & 1.77 & 12.13 \\
\hline 2 & 0.66 & 15.01 & 2 & 1.52 & 11.62 \\
\hline 3 & 0.69 & 14.46 & 3 & 1.38 & 11.36 \\
\hline 4 & 0.94 & 14.58 & 4 & 1.22 & 11.20 \\
\hline 5 & 1.05 & 14.61 & 5 & 1.12 & 11.03 \\
\hline 6 & 1.18 & 14.61 & 6 & 1.00 & 10.60 \\
\hline 7 & 1.26 & 14.25 & 7 & 1.06 & 10.65 \\
\hline 8 & 1.26 & 14.35 & 8 & 1.00 & 10.23 \\
\hline 9 & 1.34 & 14.24 & 9 & 0.87 & 9.88 \\
\hline Value & 1.37 & 14.00 & Big & 0.85 & 9.42 \\
\hline
\end{tabular}

\begin{tabular}{lll}
\hline \multicolumn{3}{l}{ Panel C: Industry Portfolios } \\
\hline \multicolumn{3}{l}{ Return (\%) } \\
portfolios & Mean & Std.dev \\
\hline Agriculture & 1.29 & 15.21 \\
Nat. resource & 1.99 & 15.96 \\
Manufacturing & 1.17 & 16.36 \\
Utility & 0.96 & 13.82 \\
Construction & 1.29 & 15.21 \\
Transportation & 0.97 & 13.29 \\
Telecom, Computer & 0.92 & 15.37 \\
Trade & 1.33 & 14.64 \\
Real Estate & 1.42 & 22.23 \\
Service & 0.85 & 14.47 \\
Mass Media & 1.04 & 15.94 \\
Comprehensive & 1.22 & 17.24 \\
\hline
\end{tabular}

a. The "Comprehensive" industry includes listed firms that are unclassified, or firms that have too many diversified businesses cross different industries.

3.2.2 B/M's predictability on monthly returns. As described earlier, Eq. (1) is a typical model to estimate the relationship between the portfolio excess returns with $B / M$.

Table 5 reports the empirical test results of B/M's predictability on monthly returns. When stocks are allocated into ten portfolios by $\mathrm{B} / \mathrm{M}$ values, the estimates show strong positive correlations between stock returns and the lagged $\mathrm{B} / \mathrm{M}$ values. The coefficients increase from 0.020 for the growth stocks to 0.076 for the value group. All portfolio coefficients have significant $\mathrm{t}$ value at the $1 \%$ level. This suggests that the $\mathrm{B} / \mathrm{M}$ ratio generally predicts higher return spreads for stocks in the value stock portfolio than in the growth stock portfolio.

When stocks are allocated into ten size portfolios, all groups show positive coefficients with $\mathrm{t}$ values significant at $1 \%$. The coefficients of explanatory variables range from 0.014 for the group with the smallest market capitalization to 0.035 for the group with the largest market capitalization, a smaller gap than that between the growth and value portfolios.

The industry portfolios also support a positive relation between expected returns and the $\mathrm{B} / \mathrm{M}$ ratios. All industry portfolios have significant slopes at the $1 \%$ level. The return spread predicted by B/M also varies across different industries. Stocks in the natural resource industry, with a coefficient of 0.069 , has higher sensitivity to $\mathrm{B} / \mathrm{M}$ than those in the comprehensive or the real estate industries, whose coefficients are 0.021 and 0.028 respectively. Overall, B/M has predictive power for most of the stocks after controlling for industry variations. 
Value Premium in the Chinese Stock Market: free lunch or paid lunch?

[Table 5] 
3.2.3 Value premium in big and small stocks. Loughran (1997) argues that there is no value premium among the largest stocks which are fewer in number than small stocks but carry heavier weights in market capitalization. While it is true that both value and small stocks have persistent premiums over growth and big stocks, we cannot rule out the possibility that the value premiums may be driven by the small stocks that generally make up a majority proportion of the sample volume when we use equally-weighted stock returns. If this is the case, the evidence of value premium may be misleading and are less important academically or practically.

To investigate this issue, we form 25 equally-weighted portfolios at the intersection of independent sorts of stocks into five size groups and five $\mathrm{B} / \mathrm{M}$ groups, respectively at their quintiles. By this independent intersectional portfolio formation method, we could directly see if value premium is limited to certain stocks (such as small stocks), or it is a pervasive premium across all size portfolios.

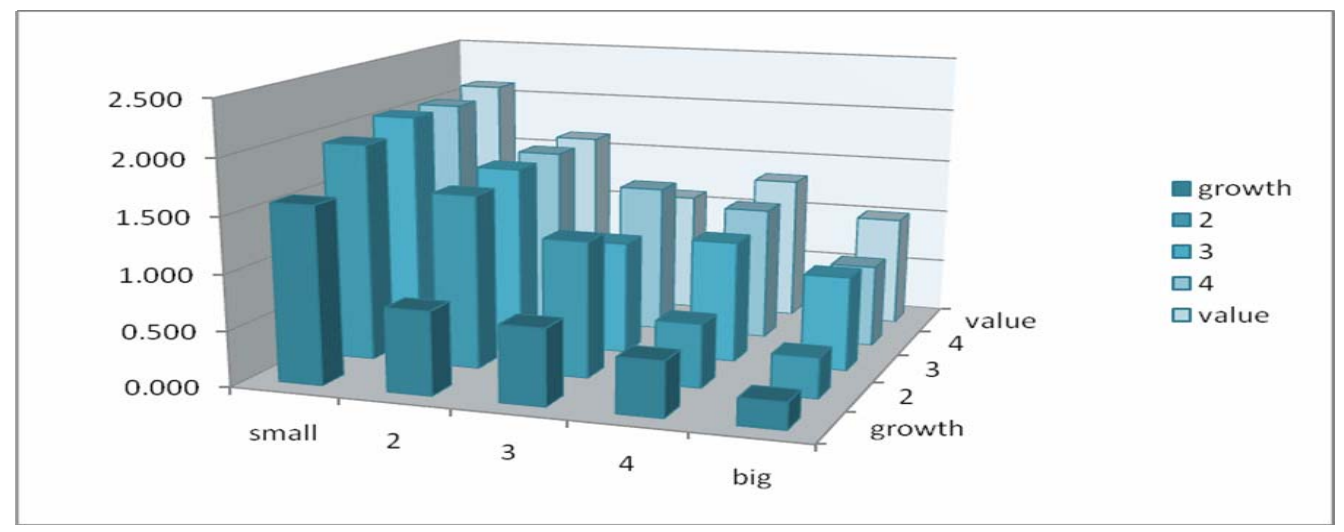

Figure 2. Monthly return under intersectional portfolio formation.

At the end of each December from 1997 to 2007, all stocks are ranked in an ascending order independently by their $\mathrm{B} / \mathrm{M}$ and market capitalizations. We then construct 25 portfolios from the intersections of $\mathrm{B} / \mathrm{M}$ and market value quintiles and calculate monthly returns. The horizontal axis is the monthly returns in percent.

Kothari, Shanken and Sloan (1995) and Loughran (1997) report a larger value premium for small stocks in the US market. In contrast, our results show that the value premium seems to be more prominent in big stocks for the Chinese market. As depicted in Figure 2, value premiums for big size portfolio are generally larger than those for small size portfolios. We also notice that the highest average return is achieved by the intersection portfolio of small and value stocks, while the lowest average return belongs to the intersection portfolio of growth and big stocks.

In sum, the above evidence provides consistent evidence for a strong positive relationship between $\mathrm{B} / \mathrm{M}$ and expected returns under all our portfolio formations. Thus, the results from both our annual and monthly returns analyses support B/M's predictive role in expected returns. However, we still need further investigation to explore what is behind such strong predictability. Specifically, we will examine the following two questions in the ensuing section: Can the value premium in China's stock market be justified by financial distress risk? What does the out-ofsample evidence of Chinese market contributes to the understanding of the relation between value premium and distress risk

\subsection{B/M, size and distress risk}


3.3.1 The logit model of distress probability. Table 6 reports summary statistics of variables that we use to distinguish distressed and non-distressed firms: debts to assets (DTA), return on assets (ROA), stock of cash over the total assets (CASHTA), current ratio (CURR), operating capital over total assets (OPCAPTA), and total asset turnover ratio (TATNOV). The selected variables are consistent with empirical evidence that proves to be most efficient in identifying financial distress risk in China's stock market (Wu and Lu (2001), Liu and Qin (2006), and Deng (2008)). We also report the results from the logit regression of the distress risk probability on the predicting variables (Equ. (2)).

Panel A of Table 6 compares the descriptive variables and reports the differences between non-distressed firms and distressed firms. The $t$ values of the variables' differences between the two subsamples are all significantly different from zero, indicating that all six variables bear statistically significant differences in the two subsamples. The average financial leverage (DTA) of non-distressed firms is 0.46 , while the DTA for distressed firms is as high as 1.10 , indicating serious insolvency among distressed firms. The average return on asset (ROA) is positive for non-distressed firms and negative for distressed firms. The stock of cash has a lower proportion in total assets in distress firms than in their counterparts, indicating a poor ability to pay principal and interest when large amount of debt is due. The distressed firms also show poor ability to cover short term debt and poor operating status as suggested by the measures of operating capital over assets (OPCAPTA), current ratio (CURR) as well as total asset turnover ratio (TATNOV). Panel B reports the summary statistics for the whole sample. Panel C reports the results of logit regression using the 15804 observations. The Pseudo $\mathrm{R}^{2}$ is 0.28 , and all six variables are statistically significant at the $1 \%$ level. Using Eq. (2), we obtain a distress probability for each firm in each year in our sample period.

In table 7, we present our estimated distress risks for portfolios sorted by (1) distress probability, (2) the B/M ratios, (3) size, and (4) industry. Panel A reports the summary statistics of distress status among different distress profitability portfolios. When the distress probability moves from the lowest group to the highest group, the financial leverage increases with the probability, while the other variables generally decrease with the probability. In Panel B, when stocks are sorted and allocated into deciles by the B/M ratio, we find little difference in distress status between value and growth firms with regard to the distress profitability. Value and growth firms have almost the same levels of ROA. Growth firms bear even more resemblance with distressed firms in terms of financial leverage and operating solvency. For example, the financial leverage is highest in growth firms and lowest in value firms, which contrasts what has been observed in the US stock market. It appears that the growth firms in China adopt a more aggressive financial policy and expose themselves to greater potential of default. On the other hand, the value firms have the highest proportion of operating capital over total assets and current ratio, indicating a better operating condition than the growth firms. Other measurements, such as CASHTA and TATNOV, are indifferent between value and growth firms.

When stocks are sorted and allocated into size deciles in Panel C, the summary statistics begin to show some consistent results. Firms in the smallest size portfolio have the highest financial leverage, and the lowest ROA, CASHTA, CURR, OPCAPTA and TATNOV, almost the same pattern with firms in the highest distress probability decile. As the size increases from the smallest group to the biggest group, the distress status indicated by our selected measures begins to alleviate with lower financial leverage, better profitability and operating conditions. In Panel $\mathrm{D}$, we report the portfolio distress status under industry classification. The construction industry 
[table 6] 
Value Premium in the Chinese Stock Market: free lunch or paid lunch?

[table7] 
has the highest proportion of debt financing among all industries, while the natural resources industry has the highest average ROA. The agriculture, telecom and computer industries appear to have better operating solvency, in terms of cash stocks and operating conditions.

3.3.2 Summary statistics for sorting variables and average portfolio returns. Table 8 presents the summary statistics of sorting variables to explore the interaction and relations among size effect, $\mathrm{B} / \mathrm{M}$ effect and distress risk. In the ten distress probability portfolios, we find that stocks with the highest estimated distress probability do have higher returns than stocks in the lowest portfolio. This, however, is not necessarily a proof that the distress risk is perceived and priced by the stock market, but rather due to public shell reverse mergers in China's stock market. China's regulation requires a relatively long preparation stage before a firm can be eventually listed on a stock exchange. The explosive demand of firms for external equity financing makes the public shell reverse merger an alternative way to IPO. A firm pursuing this routing of going public can expedite the process of getting listed by merging with a firm in ST (bankrupt) status or a listed firm that is undergoing restructuring. As a result, the "shell value" of a financially distressed firm would be allocated with a potential call option. And the higher returns obtained in the high distress probability portfolio may not be a pure response to riskreturn trade-off relations, but a noise evidence under a twisted institutions.

When stocks are allocated into ten deciles by their B/M values, the monthly returns increase almost monotonically with $\mathrm{B} / \mathrm{M}$ ratios. The average market cap is slightly higher in growth stocks than in value stocks. The average distress probability is $11 \%$ percent for growth stocks and $6 \%$ for value stocks. Apparently, value stocks do not bear a higher degree of distress risk than growth stocks. In contrast, when stocks are allocated into ten groups according to their size deciles, the estimated probability of distress almost decrease monotonically with size. It appears that the size effect is more independent from the $\mathrm{B} / \mathrm{M}$ in the Chinese stock market, as we find no significant difference in $\mathrm{B} / \mathrm{M}$ values between small and big stocks. Last but not least, when stocks are sorted by their industry classifications, the differences of estimated distress probability among different industries begin to disappear. The only industry that displays distinct characteristics from the others is the natural resource industry which has the largest average market capitalization, the highest average returns and the lowest distress risk.

\subsection{Mispricing or risk}

3.4.1 Results from unconditional three factor regressions. Table 9 reports our unconditional regression results under three portfolio allocations. In Panel A, when stocks are classified into ten portfolios according to their $\mathrm{B} / \mathrm{M}$ ratios, we find that the three-factor model absorbs a major proportion of the expected returns. The adjusted $\mathrm{R}$ squares are around 0.95 . However, there are still two groups in the lowest $\mathrm{B} / \mathrm{M}$ deciles that have significant residuals. The three-factor model provides good yet not perfect explanation for the $\mathrm{B} / \mathrm{M}$ sorted portfolio returns. The market excess return and the SMBO capture significant co-movement in stock returns. The coefficients of market excess return are significantly positive ranging from 0.92 to 1.01 with $\mathrm{t}$ values all exceeding 30, while the coefficients of SMBO are also positive, all significant at $1 \%$. The estimated coefficients of market excess return and SMBO are stable across different sorting methods. The size portfolios and industry portfolios provide similar results on the coefficients of the market factor and SMBO.

The coefficients for VMGO provide some interesting implications. In the $\mathrm{B} / \mathrm{M}$ sorted portfolios, although the coefficients of VMGO increase from -0.70 to the 0.22 as the $\mathrm{B} / \mathrm{M}$ ratios 
Value Premium in the Chinese Stock Market: free lunch or paid lunch?

[Table 8] 


\section{Table 9 Unconditional three-factor regressions, 1/1998-12/2008}

At the end of each year from 1997 to 2007, we allocate all stocks into different portfolios according to their book-tomarket ratio, market value, as well as the industry. The unconditional regression is specified as

$R_{i}-R_{f}=a_{u}+b_{u}\left(R_{m}-R_{f}\right)+s_{u} S M B O+v_{u} V M G O+\varepsilon_{i}$,

Where $R_{i}-R^{u}$ is the monthly excess return for portfolio $\mathrm{i}$, computed as the difference between portfolio return and one month deposit rate. SMBO is the return on the small size portfolio minus the return on the big size portfolio, orthogonalized with respect to the market excess return, $R_{m}-R_{f}$. And the VMGO is the return on portfolio of highest $30 \% \mathrm{~B} / \mathrm{M}$ stocks minus the lowest $30 \% \mathrm{~B} / \mathrm{M}$ stocks, orthogonalized with respect to the market excess return, $R_{m}-R_{f}$.

\begin{tabular}{|c|c|c|c|c|c|c|c|c|}
\hline \multicolumn{9}{|c|}{ Panel A: B/M portfolios } \\
\hline \multirow[t]{2}{*}{ portfolios } & \multicolumn{2}{|c|}{$\mathrm{a}$} & \multicolumn{2}{|c|}{$\mathrm{b}$} & \multicolumn{2}{|c|}{$\mathrm{s}$} & \multicolumn{2}{|c|}{$\mathrm{v}$} \\
\hline & Coeff. & $\mathrm{t}$ & Coeff. & $\mathrm{t}$ & Coeff. & $\mathrm{t}$ & Coeff. & $\mathrm{t}$ \\
\hline Growth & $-0.01^{* *}$ & -3.12 & $0.92^{* *}$ & 30.37 & $0.56^{* *}$ & 11.52 & $-0.70^{* *}$ & -5.38 \\
\hline 2 & $0.00^{*}$ & -1.99 & $0.96^{* *}$ & 39.73 & $0.56^{* *}$ & 14.48 & $-0.32^{* *}$ & -3.11 \\
\hline 3 & 0 & -1.68 & $0.96^{* *}$ & 44.82 & $0.56^{* *}$ & 16.35 & $-0.35^{* *}$ & -3.72 \\
\hline 4 & 0 & -1.11 & $0.97^{* *}$ & 49.89 & $0.65^{* *}$ & 21.04 & $-0.32^{* *}$ & -3.84 \\
\hline 5 & 0 & -0.7 & $0.97^{* *}$ & 49.14 & $0.73^{* *}$ & 23.23 & $-0.21^{* *}$ & -2.5 \\
\hline 6 & 0 & -0.29 & $0.97^{* *}$ & 47.58 & $0.74^{* *}$ & 22.87 & $-0.21^{* *}$ & -2.44 \\
\hline 7 & 0 & 0.42 & $1.00^{* *}$ & 50.62 & $0.74^{* *}$ & 23.62 & -0.12 & -1.4 \\
\hline 8 & 0 & 0.05 & $0.98^{* *}$ & 48.34 & $0.82^{* *}$ & 25.46 & -0.01 & -0.06 \\
\hline 9 & 0 & 0.67 & $1.01^{* *}$ & 43.11 & $0.82^{* *}$ & 22.11 & 0.02 & 0.2 \\
\hline Value & 0 & 0.5 & $1.01^{* *}$ & 33.96 & $0.81^{* *}$ & 17.09 & 0.22 & 1.7 \\
\hline \multicolumn{9}{|c|}{ Panel B: Size portfolios } \\
\hline \multirow[t]{2}{*}{ portfolios } & \multicolumn{2}{|c|}{$\mathrm{a}$} & \multicolumn{2}{|c|}{$\mathrm{b}$} & \multicolumn{2}{|c|}{$\mathrm{s}$} & \multicolumn{2}{|c|}{$\mathrm{v}$} \\
\hline & Coeff. & $\mathrm{t}$ & Coeff. & $\mathrm{t}$ & Coeff. & $\mathrm{t}$ & Coeff. & $\mathrm{t}$ \\
\hline Small & 0 & 0.75 & $0.95^{* *}$ & 34.78 & $1.14^{* *}$ & 26.29 & $-0.24^{*}$ & -2.06 \\
\hline 2 & 0 & -0.12 & $0.96^{* *}$ & 52.76 & $1.06^{* *}$ & 36.47 & $-0.20^{* *}$ & -2.54 \\
\hline 3 & 0 & -0.41 & $0.98^{* *}$ & 58.19 & $0.97^{* *}$ & 36.43 & $-0.21^{* *}$ & -2.9 \\
\hline 4 & 0 & -1.64 & $0.96^{* *}$ & 55.02 & $0.93^{* *}$ & 33.39 & $-0.20^{* *}$ & -2.7 \\
\hline 5 & 0 & -1.38 & $0.99^{* *}$ & 47.26 & $0.85^{* *}$ & 25.68 & -0.15 & -1.69 \\
\hline 6 & 0 & -1.72 & $0.98^{* *}$ & 45.21 & $0.73^{* *}$ & 21.03 & -0.17 & -1.77 \\
\hline 7 & 0 & -1.13 & $1.01^{* *}$ & 45.78 & $0.66^{* *}$ & 18.85 & -0.11 & -1.11 \\
\hline 8 & 0 & -1.03 & $0.98^{* *}$ & 36.45 & $0.51^{* *}$ & 11.85 & $-0.33^{* *}$ & -2.81 \\
\hline 9 & 0 & -0.58 & $0.99^{* *}$ & 36.32 & $0.33^{* *}$ & 7.66 & $-0.31^{* *}$ & -2.62 \\
\hline Big & 0 & -0.43 & $1.00^{* *}$ & 38.13 & $0.08^{*}$ & 1.96 & $-0.30^{* *}$ & -2.67 \\
\hline \multicolumn{9}{|c|}{ Panel C: Industry portfolios } \\
\hline \multirow[t]{2}{*}{ portfolios } & \multicolumn{2}{|c|}{$\mathrm{a}$} & \multicolumn{2}{|c|}{$\mathrm{b}$} & \multicolumn{2}{|c|}{$\mathrm{s}$} & \multicolumn{2}{|c|}{$\mathrm{v}$} \\
\hline & Coeff. & $\mathrm{t}$ & Coeff. & $\mathrm{t}$ & Coeff. & $\mathrm{t}$ & Coeff. & $\mathrm{t}$ \\
\hline Agriculture & -0.01 & -1.8 & $0.94^{* *}$ & 28.78 & $0.84^{* *}$ & 16.31 & -0.05 & -0.33 \\
\hline Nat. Resources & $0.02^{* *}$ & 3.26 & $1.12^{* *}$ & 19.34 & $0.19^{*}$ & 2.08 & -0.32 & -1.26 \\
\hline Manufacturing & 0 & -0.91 & $0.98^{* *}$ & 55.24 & $0.76^{* *}$ & 26.71 & -0.09 & -1.13 \\
\hline Utility & 0 & -1.15 & $0.98^{* *}$ & 28.89 & $0.62^{* *}$ & 11.6 & -0.16 & -1.07 \\
\hline Construction & 0 & -1.54 & $0.94^{* *}$ & 26.95 & $0.65^{* *}$ & 11.61 & $-0.34^{*}$ & -2.29 \\
\hline Transportation & 0 & -0.73 & $0.89^{* *}$ & 32.63 & $0.43^{* *}$ & 9.87 & -0.17 & -1.46 \\
\hline Telecom, Computer & 0 & -1.13 & $0.95^{* *}$ & 27.4 & $0.72^{* *}$ & 13.13 & $-0.62^{* *}$ & -4.14 \\
\hline Trade & 0 & 0.38 & $0.95^{* *}$ & 45.13 & $0.70^{* *}$ & 20.87 & $-0.46^{* *}$ & -5.07 \\
\hline Real estate & 0 & 0.45 & $1.01^{* *}$ & 21.89 & $0.53^{* *}$ & 7.19 & -0.14 & -0.73 \\
\hline Service & 0 & -0.93 & $0.98^{* *}$ & 37.43 & $0.70^{* *}$ & 16.73 & $-0.32^{* *}$ & -2.82 \\
\hline mass media & 0 & -0.8 & $0.96^{* *}$ & 18.68 & $0.85^{* *}$ & 10.43 & $-0.93^{* *}$ & -4.2 \\
\hline Comprehensive & 0 & -0.25 & $1.03^{* *}$ & 48.55 & $0.82^{* *}$ & 24.34 & $-0.46^{* *}$ & -5.05 \\
\hline
\end{tabular}

\footnotetext{
$*$ denotes significant at $5 \%$, and $* *$ denotes significant at $1 \%$.
} 
increase, six out of ten coefficients are significantly at the $1 \%$ level, and eight of them are indicating negative relations between VMGO and expected returns. The regressions in the size and industry sorted portfolios report similar results. We will address this issue in more depth with our results from the conditional model in the next section.

In sum, according to the unconditional results of table 9, the market excess return and SMBO act like proxies for pervasive systematic risk factors under our three different sorts. The three-factor model performs well in explaining the portfolio returns of the Chinese stock market.

3.4.2 Results from conditional three-factor regressions. Eq. (6) provides an approach to look into the reasons behind the size and the $\mathrm{B} / \mathrm{M}$ effects. If the driving force behind the value premium is, as suggested by Fama and French (1993, 1995, 1998), the pervasive distress risk factor, we expect the conditional coefficients of $\pi, a_{c}$, to be non-zero, because in such case the distress risk could largely absorb the explanatory power of its proxies, SMBO and VMGO. Correspondingly, we expect the Fama and French risk factors to become weaker by introducing distress risk and the interactions between distress risk and risk factors. On the other hand, if SMBO or VMGO are proxies for something other than distress risk, we expect the coefficient of the distress risk, $\pi$, to be indifferent from zero.

Moreover, by running the conditional regressions under different portfolio formations, we should also provide additional insights about these two factors. We argue that if a factor is priced and proxies for a certain systematic risk, we expect to find statistical and economical significance in our empirical investigation, because systematic risk, by nature, is undiversifiable and needs corresponding compensations in the expected returns. As a result, if SMBO and VMGO are proxies for pervasive risk factors, we expect to find consistent empirical evidence regardless of the way we allocated portfolios. If some noises other than risk are embraced in these two factors, however, we are supposed to find big uncertainty and changes in the statistical results of these two factors.

Table 10 reports the estimates from our conditional regressions. We find that market excess returns act as a strong determinant of expected returns across three panels as in the unconditional regressions. All the 32 coefficients of market excess returns are significant at $1 \%$ in the B/M portfolios as well as in our robustness check of size and industry portfolios. On the one hand, this result suggests that the market beta has a strong power in explaining the returns in China's stock market. On the other hand, the result may indicate a relatively high degree of stock price synchronicity that the stock returns are closely correlated with the market volatilities. As mentioned earlier, the correlation coefficient between value premium and the market excess return is as high as 0.73 . As is seen in the three panels of Table 10, beta accounts for much of the spread in the stock returns sorted by B/M, size and the industries in all periods. The explanatory power of the market excess return remains stable regardless of the way we sort portfolios.

After introducing the distress probability and its interaction terms with three Fama-French factors, 17 out of the 32 coefficients of SMBO turned statistically insignificant in three sets of conditional regressions. However, among those portfolios for which the coefficients of SMBO become insignificant, the interaction terms of SMBO and distress probability stay significantly different from zero. This indicates that SMBO is indeed closely correlated with distress probability, yet it still contains some incremental information content beyond distress risk. Moreover, only 1 out of the 32 coefficients of distress probability is significant at $5 \%$, which suggests that distress risk may not provide incremental explanatory power after controlling for 
[Table 10]-part 1 
Value Premium in the Chinese Stock Market: free lunch or paid lunch?

[Table 10]-part 2 
the three Fama-French factors. In sum, distress risk could explain a large proportion of the factor SMBO, but the distress risk doesn't necessarily drive the size factor. The industry sorted portfolios in Panel C produce similar results for the SMBO factor.

Our results for the $\mathrm{B} / \mathrm{M}$ factor are quite different from what have been found in Fama and French $(1993,2000)$. In their findings, the B/M factor provides stable and robust explanations for the average portfolio returns. However, the coefficients of VMGO reported in Table 9 and Table 10 show big volatilities across different sets of regressions. For example, in our unconditional regressions, VMGO accounts for only 19 out of the 32 groups' expected return variations, compared to 32 out of the 32 for SMBO. In our conditional regressions, only 4 out of the 32 coefficients of VMGO are significantly from zero. Neither does the interactions terms that contains $\mathrm{B} / \mathrm{M}$ display strong explanatory power. This finding suggests that VMGO does not proxy for a distinct risk factor for common stock returns in China's stock market. This contradicts the finding in the U.S. stock market.

\section{SUMMARY}

Our study has three major findings. First, we find that value premiums do exist in the Chinese stock market. From our annual return analysis, the value premiums remain positive and stable with regard to the one year contrarian strategy as well as long-term investment for 2-5 years' holding periods. Moreover, the statistics shows that the longer the holding period is, the larger the value strategy will produce. Additionally, our evidence on monthly returns also reveals a significantly positive relation between lagged $\mathrm{B} / \mathrm{M}$ and expected returns in the Chinese stock market.

Second, we find that the SMB and VMG factors may not be driven by financial distress risk. $\mathrm{SMB}$, however, shows close relation with the estimated distress probability. When the estimated distress probability is added into our conditional regressions, more than half of the coefficients of SMB turned statistically insignificant from zero. Among those coefficients that lost their explanatory power, the interactive term of SMB and distress probability stay significant from zero at the $5 \%$ level or better. With regard to $\mathrm{VMG}$, we find that the $\mathrm{B} / \mathrm{M}$ factor also appears to be unrelated with changes in distress probability, which is consistent with our observation that value stocks have lower financial leverage, indifferent profitability and operating solvency from growth firms. Moreover, the proxy for distress risk itself does not show incremental explanatory power when competing with the three Fama-French factors. As a result, the SMB factor seems to embrace more than distress risk in explaining variations in common stock returns in the Chinese stock market.

Third, we verify that VMG, the $\mathrm{B} / \mathrm{M}$ factor, may not be a proxy for systematic risk in the Chinese stock market. From the unconditional regressions, the market excess return and SMB do play a role as pervasive risk factors that provide consistent and strong explanation to the expected returns. However, the VMG factor is less robust and stable. We argue that if a factor is priced and proxies for certain systematic risk, we should be able to find statistical and economical significance in our empirical investigation. Otherwise, the empirical result will turn out differently. As mispricing will eventually be corrected after certain periods and may subject to changes in the way we form different portfolios, the empirical result will become unstable, as shown in our conditional regressions. 
Value Premium in the Chinese Stock Market: free lunch or paid lunch?

\section{REFERENCE}

Ang, A.Hodrick, B., Xing, Y., Zhang, X., 2006. The Cross-Section of Volatility and Expected Returns. Journal of Finance, 61, 259-299.

Altman, E.I., 1968. Financial ratios, discriminant analysis, and the prediction of corporate bankruptcy, Journal of Finance 23, 589-609.

Campbell, J., Hilscher, J., Szilagyi, J., 2008. In search of distress risk. Journal of Finance 63, 2899-2939.

Chan, K.C., Chen, N.F., 1991. Structural and return characteristics of small and large firms. Journal of Finance 46, 1467-1484.

Deng X. The empirical study of stock market factors in the evaluation of financial distress risk. Economics and Management Research Journal 3, 84-88.

Dichev, I. D., 1998. Is the risk of bankruptcy a systematic risk? Journal of Finance. 53, 1131-1147.

Fama, E., French, K., 1993. Common risk factors in the returns on stocks and bonds. Journal of Finance 47,427-465.

Fama, E., French, K., 1995. Size and book-to-market factors in earnings and returns. Journal of Finance 50, 131-156.

Fama, E., French, K., 1998. Value versus growth: The international evidence. Journal of Finance 53, 1975-1999.

Fama, E., French, K. 2007, Disagreement, tastes, and asset prices. Journal of Financial Economics. 3, 667-689.

Fama, E., French, K., 2008. Dissecting anomalies, Journal of Finance, 63:1653-1678.

Fama, E., 2010. My life in finance, Annual Review of Financial Economics, forthcoming.

Griffith, J., Lemmon, M., 2002. Book-to-Market equity, distress risk, and stock returns. Journal of Finance 57, 2317-2336.

Kothari, S., Shanken, J., Sloan, R., 1995. Another look at the cross-section of expected returns. Journal of Finance $50,185-224$.

Lakonishok, J.,Shleifer, A., Vishny, R.,1994. Contrarian investment, extrapolation, and risk. Journal of Finance 49, 1541-1578.

Lewellen, J., 1999. The time-series relations among expected return, risk, and book-to-market. Journal of Financial Economics 54, 5-43.

Liu J., Qin W., 2006. The possibility of financial distress of listed company. Journal of Financial Research 11, 45-54.

Lo, A., MacKinlay, A.C., 1990. Data-snooping biases in tests of financial asset pricing models. Review of Financial Studies 3, 431-467.

Loughran, T., 1997. Book-to-Market across firm size, exchange, and seasonality, Journal of Financial and Quantitatibe Analysis 32, 249-268.

Merton, R., 1973. An intertemporal asset pricing model. Econometrica 41, 867-887.

Ohlson, J. A., 1980. Financial ratios and the probabilistic prediction of bankruptcy. Journal of Accounting Research $18,109-131$.

Shanken, J., 1990. Intertemporal asset pricing: An empirical investigation. Journal of Econometrics 45, 99-120.

Sharpe, W., 1964. Capital asset prices: a theory of market equilibrium under conditions of risk. Journal of Finance $19,425-442$.

Stambaugh, R., 1986. Bias in regressions with lagged stochastic regressors. Working paper. University of Chicago.

Stambaugh, R., 1999. Predictive regressions. Journal of Financial Economics, 54, 375-421.

Wu S., Lu X., 2001. A Study of models for predicting financial distress in China's listed companies. Economic Research Journal 6, 46-55.

Zellner, A., 1962. An efficient method of estimating seemingly unrelated regressions and tests of aggregation bias. Journal of the American Statistical Association 57, 500-509. 